\title{
Antibacterial Characteristics of Lotus-Type Porous Copper
}

\author{
Jin-Soo Lee, ${ }^{1}$ Yun-Soo Lee, ${ }^{1,2}$ Mok-Soon Kim, ${ }^{1}$ Soong-Keun Hyun, ${ }^{1}$ \\ Chang-Ho Kang, ${ }^{3}$ Jae-Seong So, ${ }^{3}$ and Eui-Han Yoon ${ }^{4}$ \\ ${ }^{1}$ Department of Metallurgical Engineering, Inha University, Incheon 402-751, Republic of Korea \\ ${ }^{2}$ Light Metal Division, Korea Institute of Materials Science, Changwon 642-831, Republic of Korea \\ ${ }^{3}$ Department of Biological Engineering, Inha University, Incheon 402-751, Republic of Korea \\ ${ }^{4}$ Institute of Research \& Technology, Daechang Co., Ltd., Siheung 429-794, Republic of Korea
}

Correspondence should be addressed to Soong-Keun Hyun; skhyun@inha.ac.kr

Received 11 October 2013; Accepted 26 November 2013

Academic Editor: Nikolaos Michailidis

Copyright (C) 2013 Jin-Soo Lee et al. This is an open access article distributed under the Creative Commons Attribution License, which permits unrestricted use, distribution, and reproduction in any medium, provided the original work is properly cited.

Lotus-type porous copper with long cylindrical pores aligned parallel to the solidification direction was studied for use as an antibacterial material. The antibacterial performance of lotus-type porous copper samples with different specific surface areas against Escherichia coli was investigated. The results confirmed that the antibacterial effect gradually increased with specific surface area. The correlation between the pore structure of lotus-type porous metals and their antibacterial effect was also analyzed in detail. Our research proposes a new application of these metals in the water purifying system.

\section{Introduction}

In addition to offering convenience and many lifestyle options, industrial development has caused serious environmental contamination, especially water pollution, which increases the growth of various bacteria, viruses, and protozoa that cause water-borne diseases. Removal of disease-causing organisms from drinking water is, therefore, extremely important for human health. There are several conventional chemical disinfectants such as chlorine and its derivatives and ozone [1]. However, many of these agents are carcinogens with potential harmful side effects [2].

In this regard, several researchers have recently investigated the use of inorganic antibacterial materials such as silver and copper to inhibit microbial growth. In particular, research studies on porous antibacterial materials are well under way because the antibacterial effect is proportionate to the increase in surface area [3-5]. Shen et al. [3] evaluated the antibacterial characteristics of porous ceramic composites that were decorated with ultrafine silver (II) oxide particles and fabricated by chemical oxidation. Chen et al. [4] examined $\mathrm{Cu}-\mathrm{TiO}_{2}$ nanocomposites that could be created by photocatalytic reduction and studied their antibacterial performance in the absence of light.

Lotus-type (or Gasar) porous metals [6, 7], which have long cylindrical pores aligned parallel to the solidification direction, have many advantages over other materials for antibacterial applications. For example, the specific surface area of these metals can be easily controlled by manipulating the porosity and pore diameter $[6,8-10]$. These metals also exhibit high fluid permeability because of their low pressure drop $[6,11]$. In addition, they are easy to manufacture and are suited for mass production because their fabrication is based on the casting process $[6,8,10]$. However, the antibacterial performance of lotus-type porous metals has not been evaluated.

Here, we show the antibacterial performance of lotustype porous metals with various specific surface areas that were controlled by hydrogen gas pressure and solidification velocity $[6,8,10]$. Lotus-type porous copper was selected for the antibacterial test because copper has much higher antimicrobial activity than other metals such as silver, aluminum, silicon, and tin [12]. The correlation between pore structure and antibacterial effect will also be discussed in detail. 


\section{Materials and Methods}

2.1. Preparation of Lotus-Type Porous Copper. Lotus-type porous copper ingots with various porosities and pore diameters were fabricated by mold casting [8] and continuous casting [10] according to a previously described procedure. In brief, the fabrication of lotus-type porous copper is a continuous process comprising a series of hydrogen gas pressurization, induction melting, and directional solidification stages. Each ingot was cut into rectangular parallelepipeds $(25 \times 25 \times$ $2.5 \mathrm{~mm}^{3}$ ) by using a spark-erosion wire-cutting machine (A325; Sodick Co., Japan). Nonporous and lotus-type porous copper samples were polished with a series of emery papers, washed in ultrasonic cleaner, and finally dried in hot air. The porosity of each sample was obtained from the following equation:

$$
\operatorname{Porosity}(\%)=\left(1-\frac{\rho}{\rho_{0}}\right) \times 100,
$$

where $\rho$ and $\rho_{0}$ are the apparent density of the porous copper and the density of nonporous copper, respectively. The pore diameter was measured in the cross-section perpendicular to the solidification direction by using an image analyzer (Image-Pro Plus; Media Cybernetics Co., USA). The specific surface area was also calculated on the basis of the assumption that the pores were perfectly cylindrical.

2.2. Antibacterial Activity. Escherichia coli (E. coli; KCTC 2223) used in this study was a strain from the Korean Collection for Type Culture (KCTC, Daejeon, Korea). The nonporous and lotus-type porous copper samples were immersed in $100 \mathrm{~mL}$ of phosphate-buffered saline (PBS) solution containing approximately $10^{2} \mathrm{cfu} / \mathrm{mL} E$. coli, for specific time intervals of $15,30,45,60,90$, and $120 \mathrm{~min}$ at room temperature. To obtain the bacterial concentration, the $3 \mathrm{M}$ Petrifilm E. coli count plate method was used: $1 \mathrm{~mL}$ of the bacterial suspension was dispensed on Petrifilms by using a micropipette; the films were then placed in an incubator at $37 \pm 1^{\circ} \mathrm{C}$ for $24 \mathrm{~h}$. The antibacterial rate was determined using the following formula [13]:

$$
\text { Antibacterial rate }(\%)=\frac{N_{1}-N_{2}}{N_{1}} \times 100,
$$

where $N_{1}$ and $N_{2}$ are the bacterial count, when using the control material (304 stainless steel) and the nonporous or lotustype porous copper, respectively. The concentration of copper ions in distilled water was also verified with an inductively coupled plasma mass spectrometer (ICP-MS; ELAN 6100, Perkin-Elmer SCIEX, Canada).

\section{Results and Discussion}

Figure 1 shows the cross-sectional views perpendicular to the solidification direction of the lotus-type porous copper samples. In addition, the measured porosity, average pore diameter, and specific surface area of the samples are summarized in Table 1. The specific surface area of the lotustype porous copper samples was much higher than that of
TABLE 1: Porosity, average pore diameter, and specific surface area of nonporous and lotus-type porous copper samples.

\begin{tabular}{lcccc}
\hline & $\begin{array}{c}\text { Nonporous } \\
\text { copper }\end{array}$ & \multicolumn{4}{c}{ Lotus-type porous copper } \\
& - & 72.2 & 71.4 & 47.8 \\
\hline Porosity $(\%)$ & - & 1128.3 & 670.6 & 222.1 \\
$\begin{array}{l}\text { Average pore } \\
\text { diameter }(\mu \mathrm{m})\end{array}$ & 1.1 & 6.5 & 9.0 & 14.1 \\
$\begin{array}{l}\text { Specific surface area } \\
\left(\mathrm{cm}^{2} / \mathrm{g}\right)\end{array}$ & & & & \\
\hline
\end{tabular}

nonporous copper, and it depended on the average pore diameter and pore distribution. In particular, the specific surface area of sample $\mathrm{C}$ was almost 14 times the value for nonporous copper.

Figure 2(a) shows the antibacterial effect of nonporous and lotus-type porous copper with various specific surface areas as a function of the immersion time. The term "reference" refers to data obtained without involving copper samples. The antibacterial performance of copper gradually increased with increasing specific surface area. Figure 2(b) shows the antibacterial rate calculated using (2). It can be seen that after $30 \mathrm{~min}$ of coculturing with E. coli, the antibacterial rates of sample $\mathrm{C}$ reached $>99.999 \%$, showing strong antibacterial functions.

Figure 3 shows the number of dissolved copper ions in distilled water after immersing samples of nonporous and lotus-type porous copper (sample C) for various time intervals. These values were verified by ICP-MS analysis. The number of copper ions from the porous copper sample was much higher than that from the nonporous copper sample; the numbers increased with increasing immersion time.

There are several reasons why lotus-type porous copper showed better antibacterial performance when compared to nonporous or conventional porous copper. First, specific surface area affects antibacterial performance. The antibacterial mechanism of metallic antibacterial materials can be classified by the action of metallic ions and active oxygen generated on the surface [14]. This characterization was expected in our experiment since more E. coli were exposed to copper as the samples' specific surface area increased. The morphology of lotus-type porous metals comprised cylindrical pores aligned parallel to the solidification direction. Thus, this configuration yielded large surface areas when the ingots were cut perpendicular to the solidification direction because almost all the pores were open.

Another accelerating factor for the antibacterial performance may be crevice corrosion. Crevice corrosion is a rather aggressive form of corrosion that arises in the narrow gaps between a metal and another material, and it accelerates the elution of metal ions. In general, the corrosion behavior of porous metals is a very serious disadvantage when compared to bulk metals, particularly in case of crevice corrosion. Corrosion is also influenced by the morphology of pores and the specific surface area [15]. However, corrosion may offer a rather significant benefit from a different perspective, especially regarding the antibacterial effect. Although this experiment was conducted in the PBS solution, which has low 


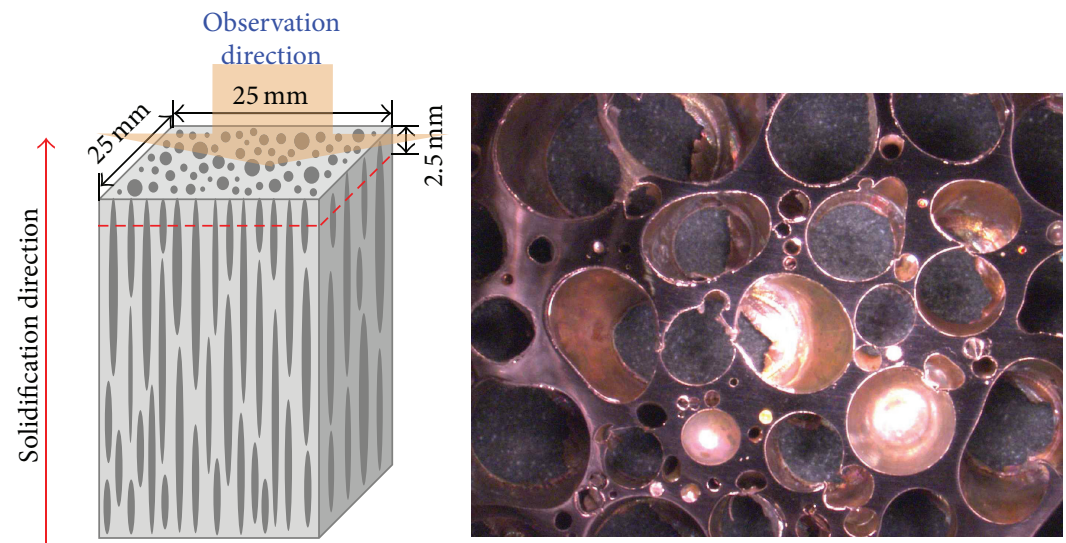

(a)

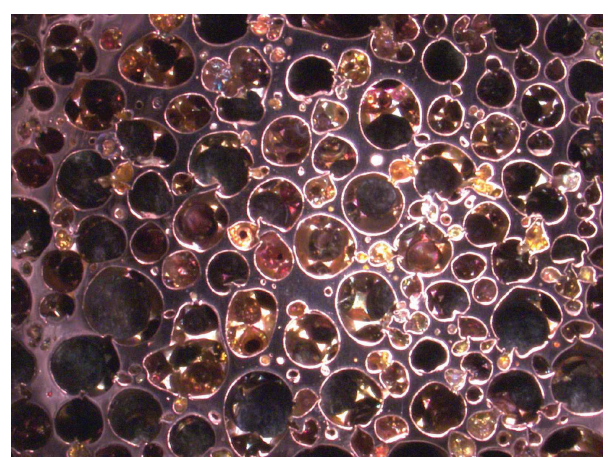

(b)

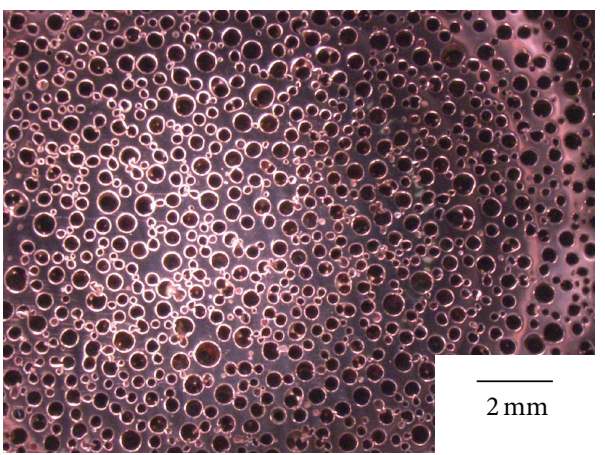

(c)

FIGURE 1: Cross-sectional views perpendicular to the solidification direction of lotus-type porous copper with various specific surface areas: (a) $6.5 \mathrm{~cm}^{2} / \mathrm{g}$; (b) $9.0 \mathrm{~cm}^{2} / \mathrm{g}$; (c) $14.1 \mathrm{~cm}^{2} / \mathrm{g}$.

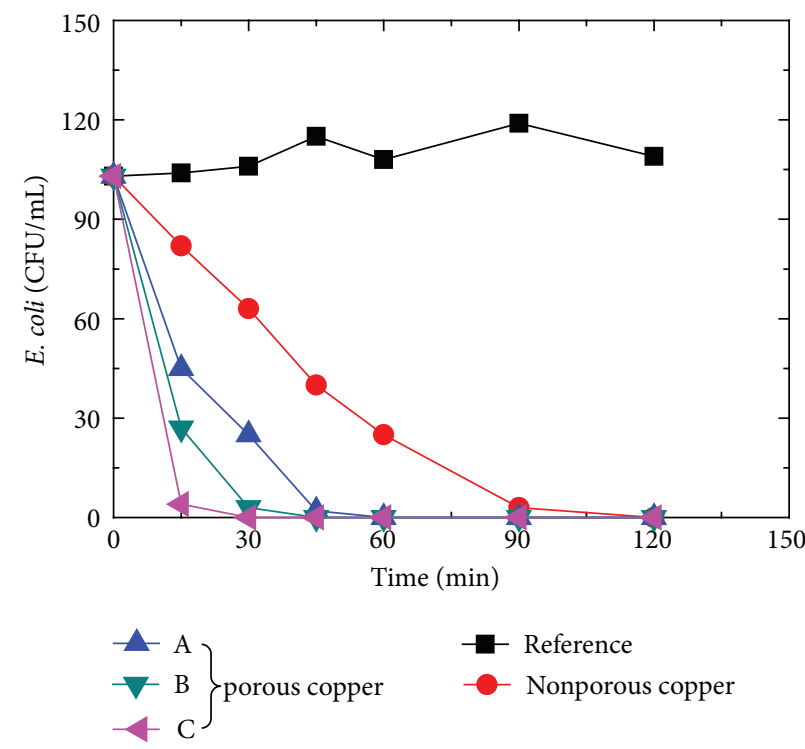

(a)

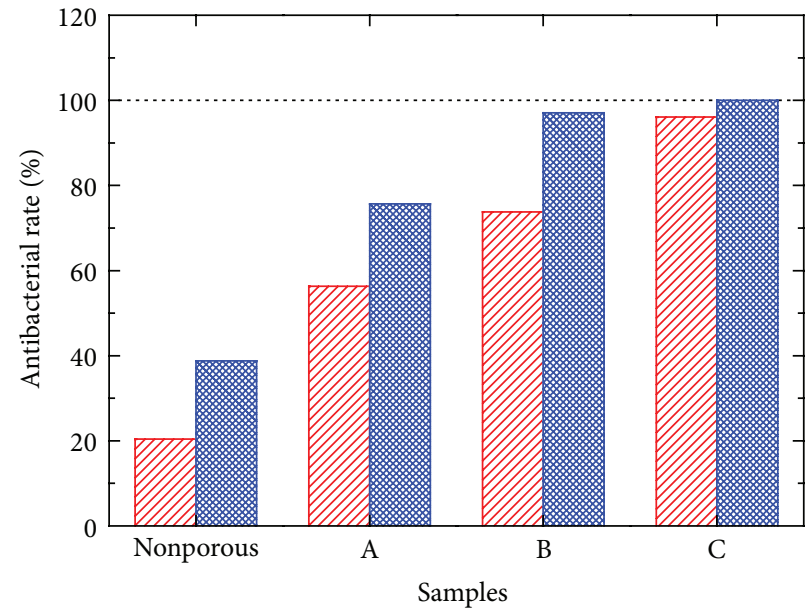

WII/A 15 in
$30 \mathrm{~min}$

Figure 2: Time-course study of the (a) population and (b) antibacterial rates of nonporous and lotus-type porous copper against E. coli. The term "reference" in (a) refers to data obtained without involving copper samples. 


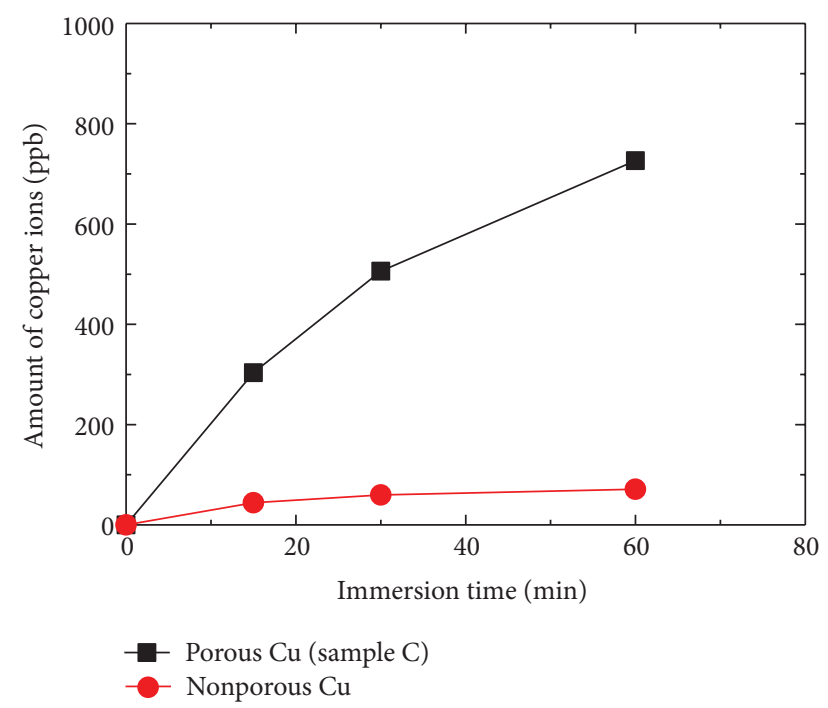

Figure 3: Number of dissolved copper ions in distilled water after immersing the nonporous and lotus-type porous copper samples for various time intervals.

chloride ion concentration and buffering capability, lotustype porous metals have many narrow pores as noted above, and the crevice corrosion effect cannot be overlooked.

\section{Conclusions}

In this study, the antibacterial performance of lotus-type porous copper was evaluated and the correlation between pore structure and the antibacterial effect was analyzed. The antibacterial performance of lotus-type porous copper gradually increased with increasing specific surface area. This was because the specific surface area and crevice corrosion behavior were influenced by the pore morphology of lotustype porous metals. Based on our research, we believe lotus-type porous metals have potential applications in the healthcare industry, especially water purifying system.

\section{Acknowledgments}

This research was supported by Daechang Grant, the Regional Innovation Center for Environmental Technology of Thermal Plasma (ETTP) at Inha University designated by MOCIE, and the Basic Science Research Program through the National Research Foundation of Korea (NRF) funded by the Ministry of Education, Science and Technology (2012007739).

\section{References}

[1] R. L. Droste, Theory and Practice of Water and Waste Water Treatment, John Wiley \& Sons, New York, NY, USA, 1997.

[2] S. D. Richardson, M. J. Plewa, E. D. Wagner, R. Schoeny, and D. M. DeMarini, "Occurrence, genotoxicity, and carcinogenicity of regulated and emerging disinfection by-products in drinking water: a review and roadmap for research," Mutation Research, vol. 636, no. 1-3, pp. 178-242, 2007.
[3] W. Shen, L. Feng, H. Feng, Z. Kong, and M. Guo, "Ultrafine silver(II) oxide particles decorated porous ceramic composites for water treatment," Chemical Engineering Journal, vol. 175, no. 1, pp. 592-599, 2011.

[4] S. Chen, Y. Guo, S. Chen, Z. Ge, H. Yang, and J. Tang, "Fabrication of $\mathrm{Cu} / \mathrm{TiO}_{2}$ nanocomposite: toward and enhanced antibacterial performance in the absence of light," Materials Letters, vol. 83, pp. 154-157, 2012.

[5] H. Jing, Z. Yu, and L. Li, "Antibacterial properties and corrosion resistance of $\mathrm{Cu}$ and $\mathrm{Ag} / \mathrm{Cu}$ porous materials," Journal of Biomedical Materials Research A, vol. 87, no. 1, pp. 33-37, 2008.

[6] H. Nakajima, "Fabrication, properties and application of porous metals with directional pores," Progress in Materials Science, vol. 52, no. 7, pp. 1091-1173, 2007.

[7] V. Shapovalov and L. Boyko, "Gasar-a new class of porous materials," Advanced Engineering Materials, vol. 6, no. 6, pp. 407410, 2004.

[8] S. K. Hyun and H. Nakajima, "Effect of solidification velocity on pore morphology of lotus-type porous copper fabricated by unidirectional solidification," Materials Letters, vol. 57, no. 21, pp. 3149-3154, 2003.

[9] M. Kashihara, S. K. Hyun, H. Yonetani, T. Kobi, and H. Nakajima, "Fabrication of lotus-type porous carbon steel by unidirectional solidification in nitrogen atmosphere," Scripta Materialia, vol. 54, no. 4, pp. 509-512, 2006.

[10] J. S. Park, S. K. Hyun, S. Suzuki, and H. Nakajima, "Effect of transference velocity and hydrogen pressure on porosity and pore morphology of lotus-type porous copper fabricated by a continuous casting technique," Acta Materialia, vol. 55, no. 16, pp. 5646-5654, 2007.

[11] H. Chiba, T. Ogushi, H. Nakajima, and T. Ikeda, "Heat transfer capacity of lotus-type porous copper heat sink," JSME International Journal B, vol. 47, no. 3, pp. 516-521, 2004.

[12] A. J. Varkey, "Antibacterial properties of some metals and alloys in combating coliforms in contaminated water," Scientific Research and Essays, vol. 5, no. 24, pp. 3834-3839, 2010.

[13] K. Liao, K. Ou, H. Cheng, C. Lin, and P. Peng, "Effect of silver on antibacterial properties of stainless steel," Applied Surface Science, vol. 256, no. 11, pp. 3642-3646, 2010.

[14] T. Yokota, M. Tochihara, and M. Ohta, "Silver dispersed stainless steel with antibacterial property," Kawasaki Steel Technical Report, no. 46, pp. 37-41, 2002.

[15] K. H. W. Seah, R. Thampuran, and S. H. Teoh, "The influence of pore morphology on corrosion," Corrosion Science, vol. 40, no. 4-5, pp. 547-556, 1998. 

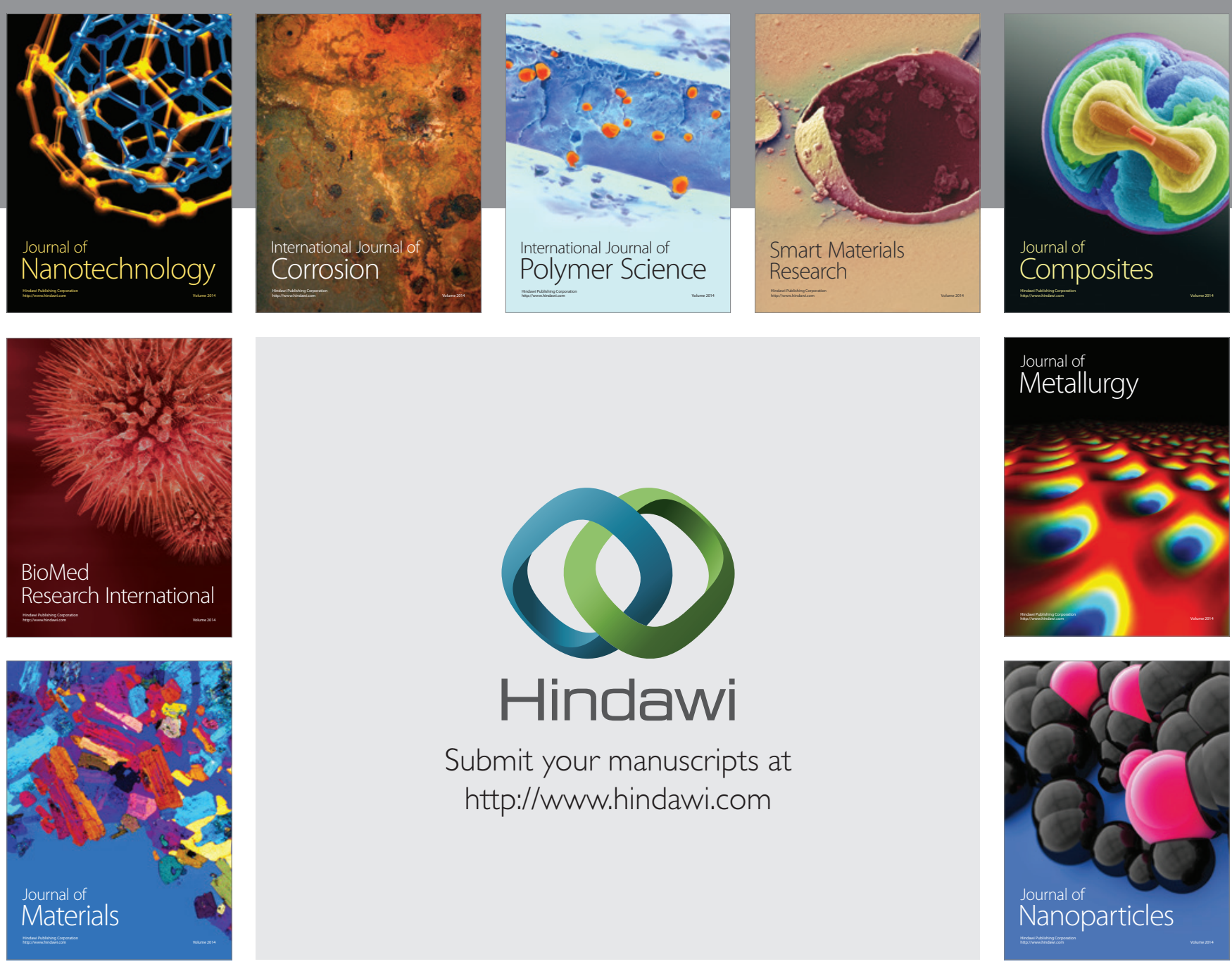

Submit your manuscripts at http://www.hindawi.com
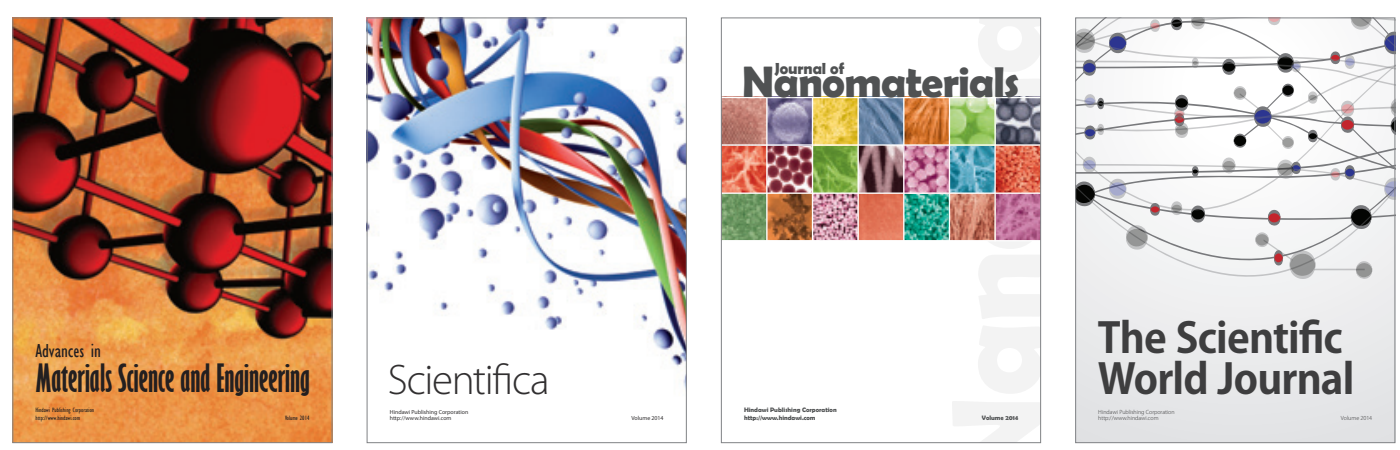

\section{The Scientific World Journal}
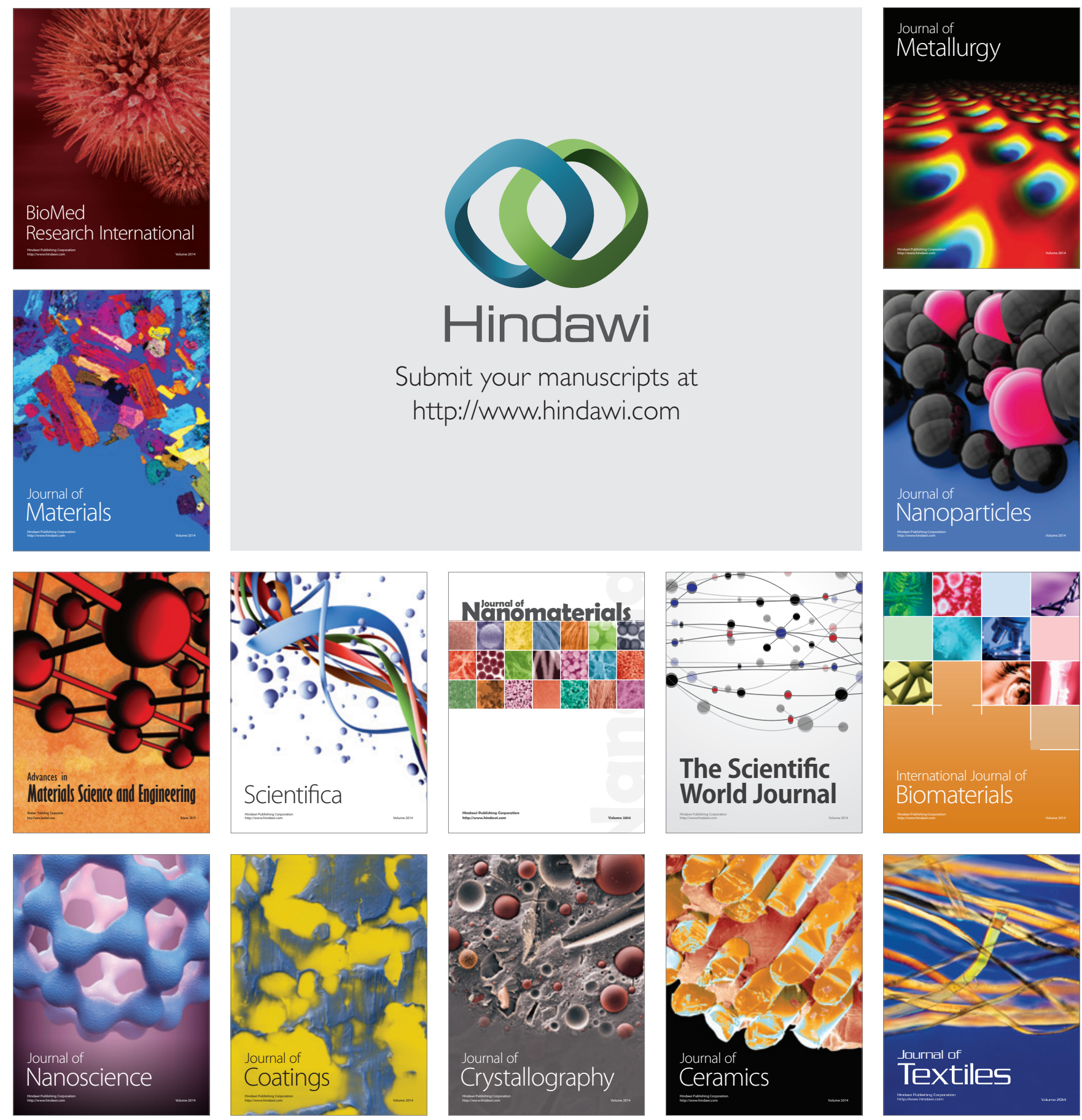